\title{
The Relationship between Teachers' Turnover Rate and Career Decision in South Korea: A Study of Private Educational Academies
}

\author{
Luis Miguel Dos Santos
}

Woosong Language Institute, Woosong University, Daejeon, South Korea. Email: luismigueldossantos@yahoo.com

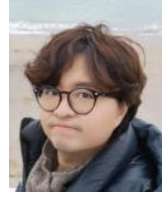

\begin{abstract}
South Korea is one of the most popular destinations for foreign language teachers wanting to start developing a career. Due to the rapid development and demands of foreign language teachers, the human resources department of the educational system is facing challenges. Many schools, including the private educational academies, always recruit language teachers for their afterschool preparational programs. However, the turnover rates for these teachers is significantly high for various reasons. This study employed the lens of the Model of Retention, Turnover, and Attrition for the exploration of 55 foreign language teachers who decided to leave their teaching position after the completion of their first-year contract. The results indicated that all participants had an unpleasant or negative experience in their social atmosphere and school environment stemming from discriminations, negative managerial styles from school administrators, and impolite practices from parents and students. Researchers, school leaders, parents, students, human resource professionals, policymakers, and government agencies should take this opportunity to reform and improve the educational environment and human resource management in South Korea.
\end{abstract}

Keywords: Discrimination, Human resource shortage, Model of retention, Turnover, Attrition, Organisational leadership, Social bias, South Korea, Teachers' professional development, Teachers' shortage.

Citation | Luis Miguel Dos Santos (2020). The Relationship between Teachers' Turnover Rate and Career Decision in South Korea: A Study of Private Educational Academies. Journal of Education and e-Learning Research, 7(2): 181-189.

History:

Received: 16 April 2020

Revised: 19 May 2020

Accepted: 22 June 2020

Published: 8 July 2020

Licensed: This work is licensed under a Creative Commons

Attribution 3.0 License $(\mathrm{cc})$ E

Publisher: Asian Online Journal Publishing Group
Funding: This study received support from Woosong University Academic Research Funding 2020.

Competing Interests: The author declares that there are no conflicts of interests regarding the publication of this paper.

Transparency: The author confirms that the manuscript is an honest, accurate, and transparent account of the study was reported; that no vital features of the study have been omitted; and that any discrepancies from the features of the study have been omitted
study as planned have been explained.

study as planned have been explained.
Ethical: This study follows all ethical practices during writing.

\section{Contents}

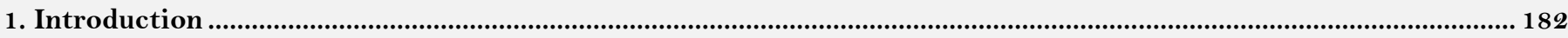

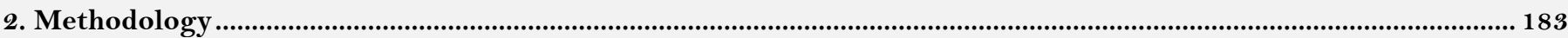

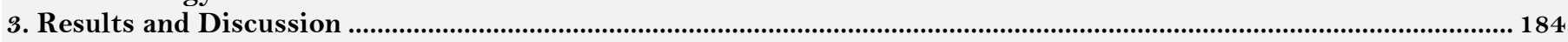

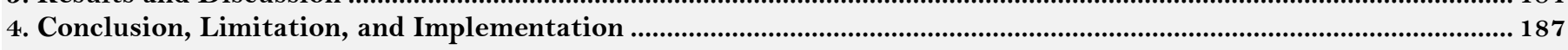

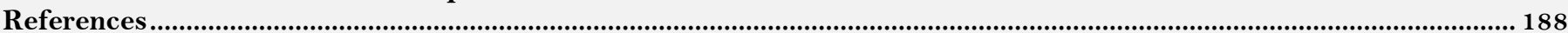




\section{Contribution of this paper to the literature}

This paper contributes to the field of organisational leadership, school human resource management, teachers' professional development, and teachers' shortage.

\section{Introduction}

Private and for-profit educational academies, also known as Hagwon in the Korean language, play a significant role in the preparation and further training of children in the contemporary South Korean educational environment. Currently, there are nearly 100,000 private educational academies in South Korean, while almost all secondary school graduates attended one of these educational services (Bousselaire, 2017). Besides the financial consideration and student enrolment management, private educational academies are facing a significant shortage of qualified teachers for their programmes and administration teams, particularly experienced teachers with a background in education and teaching (Dos Santos, 2016a, 2016b). Therefore, in order to fill the gaps of the teacher shortage, many private educational academy administrators need to hire junior-level, fresh university graduates, and even unqualified teachers to provide instructions to their students and teach their programmes.

However, due to the unstable and ineffective human resources and personnel management strategies, many teachers at these private educational academies and international schools decide to quit their teaching position within the first few years of working there (Ingersoll, 2001). In fact, the frequent departures usually creates additional costs for these private and international schools as they have to pay for additional training, accommodations, visa application fees, and even agent fees. More importantly, students may suffer as they have to continuously understand different teaching strategies, methodologies, and styles (Weiner \& Jerome, 2016). Therefore, without a stable teacher population, students may not reach the expected understanding after the completion of the programs.

Although the administration of these private educational academies create professional development plans, (Weißenrieder, Roesken-Winter, Schueler, Binner, \& Blömeke, 2015) human resource strategies, (Hanushek, Kain, \& Rivkin, 2004) that target teachers from international locations (Dos Santos, 2019b) many teachers continue to leave their teaching positions within the first few years of service. Such frequent departures have become a trend for these private educational academies in the contemporary South Korean environment. However, there are only a few studies and reports focused on the unique issues of the human resource management and practices. However, as mentioned above, the private educational academies are an important part of the current South Korean education system, particularly for university exams, preparations, and training. For junior-high and primary schools students, the private schools become the location and site of their afterschool training and programs. Therefore, although the private educational academies are not a part of the standardised and traditional educational institutions within the P12 system, researchers, school leaders, parents, students, human resource professionals, policymakers, and government agencies should pay attention to their quality and operations.

Traditional-age South Korean students need to attend one of the compulsory P12 schools based on their age during the daytime. However, due to the pressures of university admission exams (Syverson, 2007), many South Korean parents send their children to a private educational academy as one of their afterschool activities. Scholars (Kwon, Lee, \& Shin, 2017) suggested that the trends in exams and assessments created additional needs for private educational academies in many Far East cities, countries, and regions (Komatsu \& Rappleye, 2018) including but not limited to mainland China, South Korea, Japan, Taiwan, Hong Kong, and Macau (Rappleye \& Komatsu, 2018). The increased ageing population, the rise in university acceptance percentages, and the reduction of full-time career opportunities resulted in the need for further educational training that relied on forces outside the compulsory schooling to get P-12 students ready for different types of tests and exams (Alemu \& Cordier, 2017). The traditional East Asian practice affected South Korean families and parents resulting in more peer-to-peer comparison, thus leading to an increase in afterschool training and activities at private educational academies (DeWaelsche, 2015; Kim \& Seo, 2014; Lee \& Lee, 2019).

Handling the growing needs of these private educational academies is a problem throughout South Korea. The difficulties for many in South Korea is not only suppling enough student enrolment, but also ensuring the quality of teachers and school staff (Lee, Kang, \& Park, 2019). Researchers (Dos Santos, 2016b; Gardner, 2010) indicated that a dual impact approach to mediating the effects of student enrolment and school professional staff's population will increase the learning experience of students and satisfy teaching professionals in their teaching positions. Therefore, how to ensure the teachers' retention is an ongoing problem within the education environment.

One difficulty in creating high quality private educational academies is the lack of qualified, well-prepared, and satisfied teachers. The negative working environment is resulting in a negative outlook by the teachers (MartinezBeck \& Zaslow, 2006). Many private educational academies are not prepared to provide education services and to both students and teachers. The leaders and administrators of these private academies may not know how to manage employee relationships due to their lack of managerial skills and preparations (Dos Santos, 2019b). At the same time, most teachers and school staff are under-prepared, junior-level, and fresh out of university without any teaching experience (Glutsch \& König, 2019). Based on these issues, both employers and employees were not prepared for their positions at these private educational academies.

\subsection{Purpose of the Study}

South Korea is one of the most popular teaching regions for foreign language teachers to start their career development outside their home countries. Therefore, a large number of teachers have started their teaching career in South Korea (Im, Yoon, \& Cha, 2016). However, the turnover rates of these teachers is significantly high. here is a need to explore the reasons behind the background.

Without a doubt, school teachers and school professional staff are the most important human resources in any school environment (Weiner, 2012). Without school teachers, schools cannot operate any classes or services. Therefore, this study collected data from school teachers at private educational academies in South Korea. This study will explore one research question, which is, 
- Why teachers at private educational academies decide to leave their teaching positions after their first-year of services?

The researcher collected and reported the study from two directions. Career decision and development could be influenced by both the social-cultural environment of the city and the administrative leadership and management in the workplace (Dos Santos, 2019b, 2019c; Hallinger \& Heck, 2010; Rees \& French, 2010). Therefore, two possible causes were examined and investigated. As a result, the interview protocol and interview questions were designed to collect the data on these two directions. The results and discussion section is also outlined and reported based on these two directions.

\subsection{Theoretical Framework}

In order to explore the relationship between the turnover rate and career decision of teachers in South Korea, the study employed the Model of Retention, Turnover, and Attrition (Gardner, 2010) as the theoretical framework. This model was based on findings and results from various studies, including (Maslow, 1987) and (Sergiovanni, 1967). The Model of Retention, Turnover, and Attrition is a useful tool to investigate and guide a network consisting of teacher attributes, job attributes, opinions and perceptions of the workplace, job satisfaction, and their career decision. All based on the theory which mainly focuses on the personal beliefs, sense-making process, and understanding of the individuals. In other words, an individual's career decision could be influenced by a multitude of reasons. For example, in some particular geographic regions, some teachers may be influenced by the location and social isolation due to the remote location of the school (Dos Santos, 2019b). In other cases, teachers have a high level of job satisfaction due to the respectfulness from their students, parents, and school leadership (Dos Santos, 2020). Therefore, no particular theory could guide any of the participants in a positive or negative direction. For this theory, the researcher tended to focus on the reasons why teachers at these private educational academies decide to leave their teaching positions after their first-year of service in South Korea.

In the context of this study, the model described the relationship on how teacher attributes, job attributes, and teacher opinions and perceptions of the workplace could inter-influence the job satisfaction rate and teacher status. This model advocates that if teachers have negative motivation or personal belief in their job satisfaction, the results and outcomes might highly influence their career decision as a teacher. As the model is relatively new in the field of educational psychology, there are only a few research studies that have employed this model as a theoretical framework. Therefore, the result of this study may fill out the academic and professional gaps for the particular setting.

Figure 1 Refers to the theoretical framework of the model.

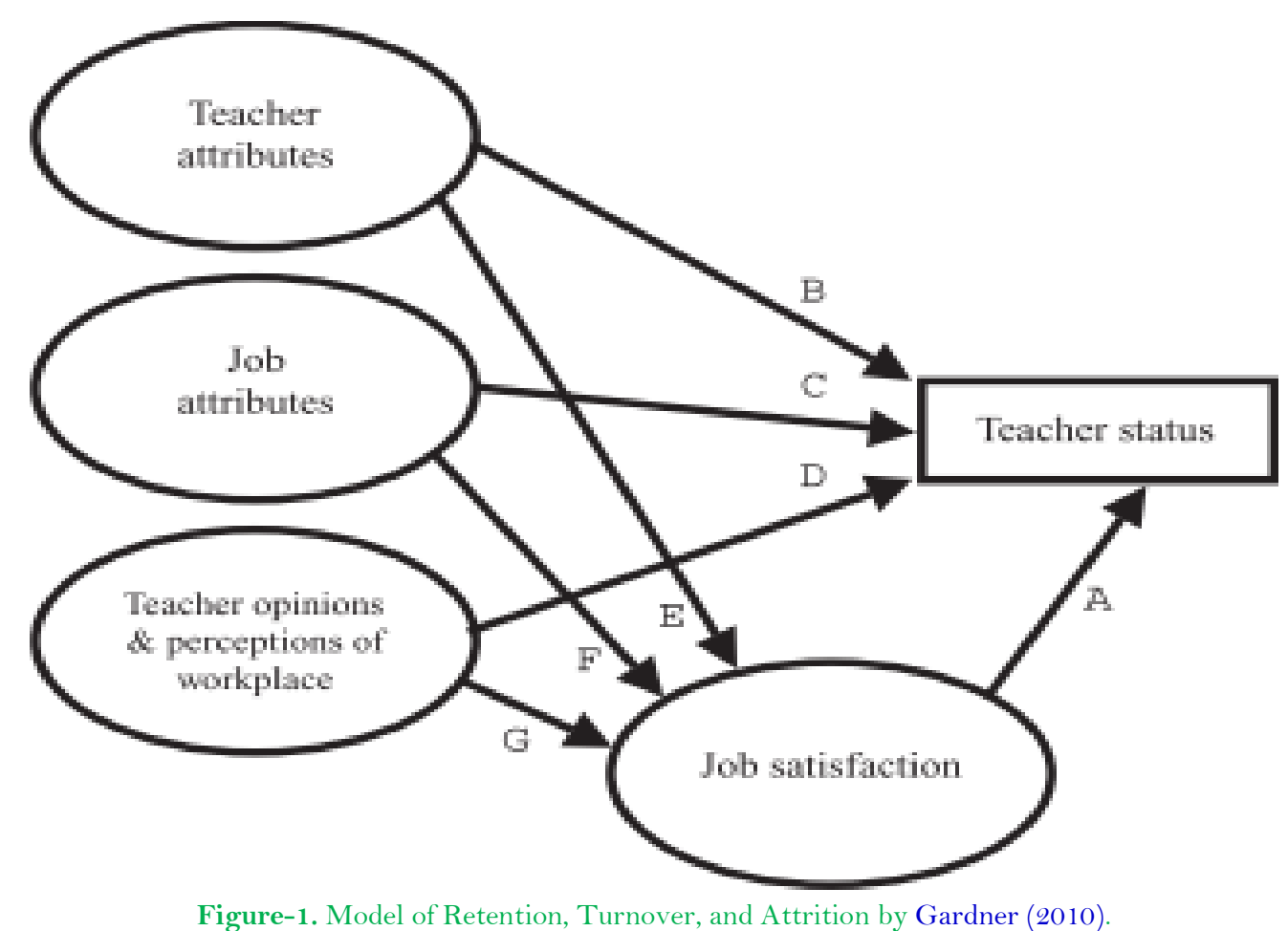

\section{Methodology}

\subsection{Background of the Participants}

This study reports on some meaningful findings regarding understanding career decision, retention, and turnover issues of a group of school teachers who are finishing their first-year contract at one of the private academies and leaving South Korea afterwards. The phenomenological analysis (Moustakas, 1994) was employed to collect data from 55 participants who are teaching foreign languages at 29 private educational academies in South Korea. Although English is one of the most popular foreign languages in the current school environment, the study was not limited to English as a Foreign Language teachers. In fact, all foreign language teachers face similar challenges and difficulties. Therefore, a wider scope of participants' background could be vital.

All the participants belonged to three social media chat groups and were willing to join this research study. More importantly, this study sought to understand why the participants decided to leave their position after their first-year teaching at private academies in South Korea. Therefore, the participants must meet the following criteria, which were:

- Currently teaching in one of the private educational academies in South Korea. 
- This is their first-year teaching in one of the private educational academies in South Korea.

- They decided to leave after their first-year contract in one of the private educational academies in South Korea.

- They are not vulnerable people.

- They are willing to share the truth, real stories and their experience.

\subsection{Data Collection}

Based on the research question and direction, the researcher developed a focus group activity protocol in order to explore the answer (Creswell, 2012; Merriam, 2009). The researcher invited 11 participants into five different sections of a designated focus group activity in a private meeting room at a community centre (i.e. each focus group activity has 11 participants). The participants in the focus group activity were asked the same interview questions and followed the same protocol procedure. Each focus group activity was hosted for 168 to 194 minutes, with two ten-minute breaks. The interview questions were developed based on the theoretical framework (Dos Santos, 2016b; Gardner, 2010) that mainly focused on the following semi-structured questions.

- Why did you select South Korea as your destination? (with follow-up questions and sharing).

- Why did you select private educational academies in South Korea? (with follow-up questions and sharing).

- What makes you like the private educational academies in South Korea? (with follow-up questions and sharing).

- What makes you dislike the private educational academies in South Korea? (with follow-up questions and sharing).

- Do you enjoy teaching at the private educational academies in South Korea? (with follow-up questions and sharing).

- Why won't you renew your contract after your first year of teaching in the private educational academies in South Korea? (with follow-up questions and sharing).

- How would you make-sense of your role, position, and teaching responsibilities at private educational academies in South Korea? (with follow-up questions and sharing).

- If you can decide one more time, do you want to teach in the private educational academies in South Korea? (with follow-up questions and sharing).

- Can you describe your teaching experience in the private educational academies in South Korea? (with follow-up questions and sharing).

- Any remarkable experiences, lived stories, events, and instances you think is significant to your teaching experience in the private educational academies in South Korea? (with follow-up questions and sharing).

During the focus group activities, the researcher recorded the conversations with an audio-recorder. After the focus group activities, the researcher listened to the conversation and transcribed the voices into written transcripts for data analysis and reporting.

\subsection{Data Analysis}

The researcher re-read the written transcripts multiple times for markings and highlighting. First, the researcher employed the general inductive approach (Thomas, 2006) to narrow down the information into the firstlevel themes via the open-coding strategy. Qualitative researchers advocated that meaningful themes and subthemes must be categorised into forms and directions for reporting. Therefore, the open-coding strategy (Merriam, 2009) is one of the most useful tools to narrow large-size data into smaller forms. Second, after the raw and large-size data information was narrowed. The researcher further narrowed down the information into the second-level themes and subthemes via the axial-coding strategy (Merriam, 2009). Afterwards, the researcher was able to categorise the data into two themes and four subthemes for meaningful reporting.

\subsection{Human Subjects Protection}

The protection of human subject and related information is significantly important and vital due to the small market in the area. In order to allow all participants to express their real-cases and lived stories for reporting, all participants were given a pseudonym to remain anonymous to potential employers and human resource professionals. Also, all participants in the focus group activities have not disclosed any data, including but not limited to personal contact, shared real-cases and lived stories, to any third-party after the focus group activities. Also, during the focus group activities, their real name and contact number were kept private. Everyone used their assigned pseudonym for addressing (Creswell, 2012).

After the data collection, the signed and unsigned agreements, content forms, personal contacts, data information, recording, written transcripts, computer, and related documents were locked in a password-protected cabinet. Only the researcher has the rights to read the materials. After the data analysis procedure, the related materials were deleted and destroyed in order to protect the privacy of all parties.

\section{Results and Discussion}

After the researcher categorised more than 358 pages of written transcripts, the researcher categorised two themes and four subthemes for reporting. Although teachers decided to leave their positions for various reasons, most of the themes and subthemes (i.e. reasons) concerned a similar background. During the focus group activities, the participants shared 'hate South Korea' 156 times, 'machine' 134 times, 'bad or terrible management' 109 times, 'awful job' 54 times, 'unfair' 50 times, and 'slavery' 21 times. Through this qualitative study, the researcher could complete an inductive analysis of the data information and categorised meaningful themes. Table 1 refers to the themes and subthemes for the study. 
Table-1. Themes and subthemes.

\begin{tabular}{r|l|l}
\hline \multicolumn{2}{l}{ Themes and Subthemes } \\
\hline 1. & Unpleasant social and cultural experience \\
\hline & 1.1. & Discrimination based on skin colour \\
\hline & 1.2. & Discrimination based on gender \\
\hline 2. & Unpleasant administrative style of the school environment \\
\hline & 2.1. & No respectfulness from the school leadership \\
\hline & 2.2. & No respectfulness from the parents and students \\
\hline
\end{tabular}

\subsection{Unpleasant Social and Cultural Experience}

South Korea is an East Asian region that shares a significant element of both Chinese and Japanese cultures. Although Korean culture has many special customs and traditions, many of the historical sites, languages, customs, food cultures, religious behaviours, and practices were adopted from China and Japan (Xiao \& Hu, 2019). Therefore, many participants with Chinese or Japanese teaching and learning experiences found that the Korean cultures shared significant cultures and practices with the neighbouring countries (Chung, 2016). Although South Korean cultures adapted a lot of Chinese and Japanese practices, all participants expressed negative experiences from their teaching and employment practices, particularly in the areas of skin colours and gender.

\subsubsection{Discrimination Based on Skin Colour}

Only five out of the 55 participants were East Asian people, while the other 50 were non-East Asian (i.e. Africans, Caucasians, Latino/as, South-eastern Asians). Although the researcher did not mention any ideas about discrimination and skin colour during the focus group activities, all expressed a lot of sharing and lived stories about these issues of their social and cultural experience in South Korea. The following reported the sharing of their living experience in the community.

First, surprisingly, all African teachers $(\mathrm{N}=12)$ expressed a large number of negative comments about the discrimination cases toward their skin colours in the community, one said,

Almost once per week, some random Korean would ask me why my skin colour is so dark. They asked me if I like to drink ink or black bean soup every day... they even asked me... the skin colours of my dad and mom. It was so impolite and rude...(Teacher\#34)

Several African teachers had teaching and learning experiences in Japan and China, and they all expressed positive and supportive feedback and experience, many said they are going back to Japan for a better living environment, one said,

In Japan, I can live as a teacher or a general resident with respectfulness from other friendly people in the city. But in Korea, it was so random. People like to gaze at me when I am walking on the street. It is so annoying...(Teacher \#22)

Two participants expressed their extreme cases toward their skin colours in a metropolitan city in South Korea. These two participants were called 'gorilla' in a park. However, the parents did not stop the children and educate them. Instead, the parents encouraged the children to discriminate, one said,

In the United States, when children did something wrong, their parents always asked them to say sorry and teach them the correct ways...two children in the park called me African Gorilla and laughed at me for a minute...but their parents never stopped them but asked me to leave the park, Jesus (Teacher \#44)

In short, besides African teachers who had experienced negative discriminations toward their skin colours and background, all other teachers also experienced similar cases regardless of their skin colours (e.g. Caucasian, Latino/as etc.). A previous study (Choi, 2001) indicated that the discriminations based on skin colours, language, nationality, and place of origin were not new in the current South Korea environment. Many ethical Korean people who were born in China faced a similar situation even they are Korean citizens.

Second, all Latino/as teachers expressed a similar case toward their skin colours and nationalities. The United States, Australia, Canada, and the United Kingdom are some countries known as the social and cultural friendly places where people with different skin colours can live together (Lenzi et al., 2017). It is not uncommon for immigrants to settle and invest their life in these countries. Therefore, some participants with Latino/as background with native or near-native language proficiency decided to invest their teaching career development after university graduation in the East Asian region. However, all eight $(\mathrm{N}=8)$ Latino/as teachers expressed a negative experience due to their skin colours and nationalities. For example, one shared that parents and children called her an illegal immigrant to the United States due to her skin colour and cultural background, she said,

The border between the US and Mexico attracts many illegal immigrants for many years... but I was born and raised

in the US...If someone called me illegal immigrant due to my skin colour or whatever in the US, I could call the polite for discrimination... no excuse can be given for sure...(Teacher \#3)

Another Latina American teacher also expressed a similar case due to her skin colour and physical outlook. The participant said that many residents in the city asked her to go back to Mexico because of her face, she said,

... all foreigners in this region lived with valid visa regardless of their nationalities...I had many Filipino friends, but

it does not mean I must be a Filipina. Regardless of my nationality or what, asking me go back to the Philippines is extremely rude... I have never experienced that in Japan and China...(Teacher \#2 1)

Surprisingly, Caucasian teachers from South Africa also faced discrimination because of their white skin colour. In the South Korean perspective, people from African countries should be black people, although people from the Middle East region always lived in the northern African region. Many public members challenged the participants about how they gained their South African nationality, one said,

... some random Korean person asked me how can I gained my South African citizenship as Mandela is a black man...I think this is a very ugly question and I didn't want to answer...but the Korean people... not just one, a bunch of them asked the same question within these months... my God (Teacher \#39)

In short, regardless of the various skin colours, all participants expressed discrimination based on their skin colour from many South Korean people in the community (Choi, 2001). These types of questions encouraged them 
to leave the region as these questions were full of discrimination, social bias, and social stigma. It is worth noting that the discrimination toward some unchangeable elements, such as skin colours, nationality, and place of origin always discourage individuals' career decision and career development (Dos Santos, 2019b). Many advocated that although the Korean government always believed it is ready for globalisation, the residents and public members were totally not ready, particularly with respect to culture understanding (Kim \& Seo, 2014; Lee \& Lee, 2019). Some have reported the cases to the police station, but no results were produced. Therefore, many decided to leave the region after their contract.

\subsubsection{Discrimination Based on Gender}

Gender is another significant issue for the turnover rates among these teachers in South Korea (Kim \& Park, 2018). Female rights are an arguable issue in the contemporary South Korean environment. Although the South Korean government argued that the region is fighting for women's rights and authorities, it is not uncommon to find a lot of negative news toward female individuals due to their gender. The following section reported the firsthand experience from the frontline foreign teachers (i.e. both male and female teachers) who experienced discrimination due to their gender.

From the female participants' expressions, all experienced different levels of discrimination due to their gender in the current South Korean society. For example, several indicated that they were forced to give up their seats on subways and buses to other male passengers and elderly, one said,

As an African female foreign resident in South Korea, I have to give up my seat to other male South Korea here...I sounded like I am going back to the early 1900s, the time of Rosa Parks...I argued my rights to other passengers, but no one was standing with me including all other female people (Teacher \#12)

Besides giving up the seats, many female participants indicated that they had to allow male Korean people and elderly the priority to many services, such as cashier, bank queue, government services, and hospital waiting line due to their gender. One said,

I am willing to give up my services and seats to other people who needed the faster services. I have to give it up by myself...not by force. However, those people here expected you give up your services to others... that's unfair and irresponsible (Teacher \#18)

Although all female participants faced different types of discriminations based on their gender, all male participants experienced negative situations due to their gender as well. For example, several participants had facial hair as their fashion style. However, they shared that many South Korean people called them dirty men and barbarians. One said,

I have had my facial hair for more than 20 years. I don't think that is a problem...this is not illegal... if they think that is illegal to have facial hair, send me to the court. But those people... random people on the street called me a dirty man because I have long facial hair...(Teacher \#55)

Besides facial hair, several male participants who had long hair also experienced similar situations and oral harassments from other residents in South Korea. The following captured one participant's life experience.

I am a pop music lover, and I have my own band in the UK and South Korea... having long hair is not unlawful, right? But once, at night, an old man brought a scissor and tried to cut my hair... he wasn't drunk. But I could see he wasn't pleasant... I ran away to a convenience store...I almost needed to call the police (Teacher \#8)

In short, the researcher captured several significant sharing and lived stories about dealing with discrimination problems with skin colour and gender in the current South Korean society. It is worth noting that all participants experienced different types of discrimination issues which encouraged their departure from their career development in this region. In reflecting the Model of Retention, Turnover, and Attrition by Gardner (2010) teachers attributes toward the external and social environmental elements, and factors highly influenced their career decision and career development in South Korea. In fact, based on the Model of Retention, Turnover, and Attrition, the element of teacher attributes could impact teachers' status and job satisfaction. For this section of the outcomes and results, the researcher advocated that the negative experiences from the social bias and social stigma had the significant factors toward teachers' status (Dos Santos, 2019a, 2020).

\subsection{Unpleasant Administrative Style of the School Environment \\ 3.2.1. No Respectfulness from the School Leadership}

The environmental factors of this society encourages or discourages the career decision and career development of individuals, particularly foreign language teachers who are teaching at one of the hosted countries without prior living experience internationally. Usually, international school teachers and school professional staff do not have strong connections and networks in hosted countries. For most of the cases, school administrators and co-workers were their first friends and peers for support (Chandler, 2010; Hardman, 2001; Ingersoll., 2001). However, it is worth noting that all participants expressed negative experiences about the school leadership and managerial styles (Darling-Hammond, 2003; Ingersoll \& Smith, 2003) always influenced their career decision and career development in South Korea.

All participants expressed they had an excessive workload and long working hours of their position. Many expressed needing overtime payment and an extra holiday due to the excessive working hours and workload weekly. They received nothings from their employers, one said,

The management of the school is very terrible. I worked as a money-making machine for more than 50 working hours every week. I reported this terrible situation to the international centre for help...they could not help at all but ask me to understand this is the working environment in South Korea (Teacher \#4)

After this participant completed her sharing, all echoed and expressed many similar situations, one said,

I can totally confirm what she shared. I work as a slave in the school. I have to stay in the school at 8 AM in the morning and stay until \& PM. They gave me several breaks in between, but that's not really something... I need to rest and a break (Teacher \#45) 
Nearly 30 participants advocated that their school leaders asked them to teach excessive working hours and exceed student-capacity which were not listed on their contract. They shared that their employers promised additional salary and wages, but no money was received. One said,

I only need to teach up to 20 students in a classroom based on my contract...the contract said if there are additional duties, I will receive additional hourly payment... but of course, I received nothing... I reported that to the ministry and the international centre, but the staff helped the employers instead...I could not access the CCTV. What can I do? (Teacher \#31)

The workload arrangement was a problem among the participants, particularly teachers from lower social status countries or teachers of colour. Many advocated that society is full of social bias and social stigma (Choi, 2001). They also expressed as long as the school is a safe shelter, they are willing to continue. However, many expressed the opposite (i.e. an unsafe and unfair working environment). The researcher asked the focus group what types of unsafe situations and unfairness could be found in their workplace, and one said,

I have my real name, my first name and last name. People should call me in a legal way. But my employer gave me a nickname based on my physical condition. I think that is very unpleasant. I asked her to stop that. But she told me that she could not understand English... She never said that in front of me, but I could hear how she used my ugly nickname with other Korean people and parents...(Teacher \#41)

In short, school leadership and managerial styles influenced the career decision and career development of most of the participants in this study (Dos Santos, 2019c; Farmer et al., 2016). In fact, many teachers wanted to spend their power and energy helping their schools and students. However, the social stigma and social bias toward them discouraged that decision. Therefore, based on the group sharing, everyone decided to leave the region after their first-year contract. In reflecting the Model of Retention, Turnover, and Attrition by Gardner (2010) teachers' opinions and perceptions of the workplace always influenced the job satisfaction and the career decision and development of the teachers. The above results indicated that due to the disrespectfulness from the school leadership, many teachers had very low-level job satisfaction which encouraged them to leave their position after their first-year contract. A previous study (Dos Santos, 2019b) indicated that if teachers do not have the sense of belonging of their school, they were more likely to leave the school for a better and more appropriate opportunity. In this case, some teachers who used to teach in China and Japan advocated that their prior experience offered them positive memories. Therefore, previous experience, personal background, and lived stories always influenced and impacted the career decision and career development of individuals.

\subsubsection{No Respectfulness from the Parents and Students}

After sharing their unpleasant experience about their school leadership and managerial style (Hallinger \& Heck, 2010), the focus group members also discussed that the negative experience and social bias from the parents and students were vital. For example, as mentioned above, some school administrators and parents gave a nickname to the teachers based on their physical conditions. A previous study (Ullman, 2020) indicated that many teachers experienced parental discrimination based on some unchangeable elements, such as gender and skin colour. As a result, the discriminations from parents and students served as factors for career decision and career development. Besides, in this case, some parents also used the nationality and citizenship to address the participants' instead of their name, one said,

... some parents want their children in the British teachers' classroom due to the accent, some preferred American...I understood that...however, those parents called us American woman, British teacher, African black man...that's really impolite...I asked them to address my name instead of my citizenship. But those people never listen (Teacher $\# 10$ )

In addition, all participants expressed the unpleasant and disrespectfulness of both parents and students. From the perspectives of the parents, many participants expressed that the parents never showed respectfulness as they were not the standardised P12 classroom teachers in the public and private school environment. For example, one expressed that the parents ordered her classroom instructions during her lessons, said,

A parent entered my classroom without any permission... she ordered me to teach her kid in this way or in that way. She told me that my lesson was too easy. She wanted more assignments and activities exclusively for her child... That's my classroom. But she invaded my lesson and ordered me... what a horrible situation (Teacher \#1)

Students also understood the status and position of their teachers from the private educational academies (i.e. non-standardised P12 school teachers). Therefore, many students expressed negative attitudes and tempers to the participants. For example, many expressed that their students threw the assignments at the participants as the assignments could not meet their expectations, one said,

My co-workers and I designed some grammar training and exercise papers for the $9^{\text {th }}$ graders. We always asked them to hand in the assignment the next day...But we are not qualified teachers at the public school system. Those students don't respect to us... They threw their assignments in front of us...on the floor asked us to pick it up...never listen to our orders and lesson...(Teacher \#53)

In short, in this study, many participants faced discriminations from the society, school administrators, parents, and students due to their unchangeable elements, such as skin colour, gender, nationality, place of origin, and even status of their role (e.g. non-standardised P12 teachers). Therefore, in reflecting the Model of Retention, Turnover, and Attrition by Gardner (2010) the external environment of the workplace and the teachers' opinion and perceptions of the workplace were negative. Such negative elements and factors impacted job satisfaction, which eventually encouraged the departures of the participants in this study.

\section{Conclusion, Limitation, and Implementation}

In reflecting the Model of Retention, Turnover, and Attrition by Gardner (2010) most participants advocated that the teacher attributes about the external environmental factors, and the teachers' opinions and perceptions of workplace always influenced their job satisfaction with the career decision and career development at one of the private educational academies in South Korean. Besides the teacher's career decision and career development, it is worth noting that the discriminations, social biases, and social stigmas were significantly serious toward foreign 
language teachers and foreigners in South Korea. The results further indicated how social and cultural environments influence human resource management problems in South Korea. Although the South Korean government always advocates that South Korean environments and societies are free and friendly to all foreigners and workers, the results indicate that there is still room for improvement, particularly in the perceptions of the public members.

Every study has its own limitation. This current study only interviewed participants who are currently teaching at one of the private educational academies. This study could expand the populations to school leaders and administrators in order to increase the rich and in-depth data information. Therefore, future research studies may focus on this direction for a richer and wider picture. Nevertheless, this research study explored and discovered meaningful information about a teacher's career decision and career development as well as the social and cultural problems of foreigners in South Korea. Researchers, school leaders, parents, students, human resource professionals, policymakers, and government agencies should take this opportunity to reform and improve the educational environment and human resource management in South Korea.

\section{References}

Alemu, A. M., \& Cordier, J. (2017). Factors influencing international student satisfaction in Korean universities. International Journal of Educational Development, 57, 54-64.Available at: https://doi.org/10.1016/j.ijedudev.2017.08.006.

Bousselaire, S. (2017). Hagwon in South Korea. Retrieved from https://borgenproject.org/hagwons-south-korea/.

Chandler, J. (2010). The role of location in the recruitment and retention of teachers in international schools. Journal of Research in International Education, 9(3), 214-226.Available at: https://doi.org/10.1177/1475240910383917.

Choi, S. (2001). Gender, ethnicity and market forces: Observations of ethnic Chinese in Korea. New York: Routledge.

Chung, S.-Y. (2016). To have or to be? Narrating confucian value in contemporary Korea. International Communication of Chinese Culture, 3(4), 631-643.Available at: https://doi.org/10.1007/s40636-016-0068-8.

Creswell, J. (2012). Qualitative inquiry and research design: Choosing among five approaches. Thousand Oaks, CA: Sage.

Darling-Hammond, L. (2003). Keeping good teachers: Why it matters, what leaders can do. Educational Leadership, 60(8), 6-13.

DeWaelsche, S. A. (2015). Critical thinking, questioning and student engagement in Korean university English courses. Linguistics and Education, 32, 131-147.Available at: https://doi.org/10.1016/j.linged.2015.10.003.

Dos Santos, L. M. (2016a). Foreign language teachers' professional development through peer observation programme. English Language Teaching, 9(10), 39-46.Available at: https://doi.org/10.5539/elt.v9n 10p39.

Dos Santos, L. M. (2016b). Relationship between turnover rate and job satisfaction of foreign language teachers in Macau. Journal of Educational and Developmental Psychology, 6(2), 125-134.Available at: https://doi.org/10.5539/jedp.v6n2p 125.

Dos Santos, L. M. (2019a). Investigating employment and career decision of health sciences teachers in the rural school districts and communities: A social cognitive career approach. International Journal of Education and Practice, 7(3), 294-309.Available at: https://doi.org/10.18488/journal.61.2019.73.294.309.

Dos Santos, L. M. (2019b). Recruitment and retention of international school teachers in remote archipelagic coun tries: The Fiji experience. Education Sciences, 9(2), 1-16.Available at: https://doi.org/10.3390/educsci9020132.

Dos Santos, L. M. (2019c). Rural public health workforce training and development: The performance of an undergraduate internship programme in a rural hospital and healthcare centre. International Journal of Environmental Research and Public Health, 16(7), 124.Available at: https://doi.org/10.3390/ijerph 16071259 .

Dos Santos, L. M. (2020). International school science teachers' development and decisions under social cognitive career theory. Global Journal of Engineering Education, 22(1), 51-56.

Farmer, T. W., Chen, C.-C., Hamm, J. V., Moates, M. M., Mehtaji, M., Lee, D., \& Huneke, M. R. (2016). Supporting teachers' management of middle school social dynamics: The scouting report process. Intervention in School and Clinic, 52(2), 67-76.Available at: https://doi.org/10.1177/1053451216636073.

Gardner, R. D. (2010). Should I stay or should I go? Factors that influence the retention, turnover, and attrition of K-12 music teachers in the United States. Arts Education Policy Review, 111 13), 112-121.Available at: https://doi.org/10.1080/10632910903458896.

Glutsch, N., \& König, J. (2019). Pre-service teachers' motivations for choosing teaching as a career: Does subject interest matter? Journal of Education for Teaching, 45(5), 494-5 10.Available at: https://doi.org/10.1080/02607476.2019.1674560.

Hallinger, P., \& Heck, R. H. (2010). Collaborative leadership and school improvement: Understanding the impact on school capacity and student learning. School Leadership and Management, 30(2), 95-1 10.Available at: https://doi.org/10.1080/13632431003663214.

Hanushek, E. A., Kain, J. F., \& Rivkin, S. G. (2004). Why public schools lose teachers. Journal of Human Resources, 39(2), 326-354.Available at: https://doi.org/10.2307/3559017.

Hardman, J. (2001). Improving recruitment and retention of quality overseas teachers. In S. Blandford \& M. Shaw (Eds.), Managing International Schools (pp. 123-135). London, UK: Routledge Falmer.

Im, S., Yoon, H.-G., \& Cha, J. (2016). Pre-service science teacher education system in South Korea: Prospects and challenges. Eurasia Journal of Mathematics, Science E Technology Education, 12(7), 1863-1880.Available at: https://doi.org/10.12973/eurasia.2016.1533a.

Ingersoll, R. M., \& Smith, T. M. (2003). The wrong solution to the teacher shortage. Educational Leadership, 60(8), 30-33.

Ingersoll, R. M. (2001). Teacher turnover and teacher shortages: An organisational analysis. American Educational Research Journal, 38(3), 499-534.Available at: https://doi.org/10.3102/00028312038003499.

Kim, M. S., \& Seo, Y. S. (2014). Social cognitive predictors of academic interests and goals in South Korean engineering students. Journal of Career Development, 41(6), 526-546.Available at: https://doi.org/10.1177/0894845313519703.

Kim, E., \& Park, H. (2018). Perceived gender discrimination, belief in a just world, self-esteem, and depression in Korean working women: A moderated mediation model. Women's Studies International Forum, 69(July-August), 143-150.Available at: https://doi.org/10.1016/j.wsif.2018.06.006.

Komatsu, H., \& Rappleye, J. (2018). Is exam hell the cause of high academic achievement in East Asia? The case of Japan and the case for transcending stereotypes. British Educational Research Journal, 44(5), 802-826.Available at: https://doi.org/10.1002/berj.3468.

Kwon, S. K., Lee, M., \& Shin, D. (2017). Educational assessment in the Republic of Korea: Lights and shadows of high-stake exam-based education system. Assessment in Education: Principles, Policy \& Practice, 24(1), 60-77.Available at: https://doi.org/10.1080/0969594X.2015.1074540.

Lee, J. S., \& Lee, K. (2019). Perceptions of English as an international language by Korean English-major and non-English-major students. Journal of Multilingual and Multicultural Development, 4O(1), 76-89.Available at: https://doi.org/10.1080/01434632.2018.1480628.

Lee, J.-A., Kang, M. O., \& Park, B. J. (2019). Factors influencing choosing teaching as a career: South Korean preservice teachers. Asia Pacific Education Revierw, 20(3), 467-488.Available at: https://doi.org/10.1007/s 12564-019-09579-z.

Lenzi, M., Sharkey, J., Furlong, M. J., Mayworm, A., Hunnicutt, K., \& Vieno, A. (2017). School sense of community, teacher support, and students' school safety perceptions. American Journal of Community Psychology, 60(3-4), 527-537.Available at: https://doi.org/10.1002/ajcp.12174.

Martinez-Beck, I., \& Zaslow, M. (2006). Introduction: The context for critical issues in early childhood professional development. In M. Zaslow \& I. Martinez-Beck (Eds.), Critical issues in early childhood professional development (pp. 1-16): Paul H Brookes Publishing.

Maslow, A. H. (1987). Motivation and personality (3rd ed.). San Francisco, CA: Harper \& Row Publishers.

Merriam, S. B. (2009). Qualitative research: A guide to design and implementation. San Francisco, CA: Jossey Bass.

Moustakas, C. (1994). Phenomenological research methods. Thousand Oaks, CA: Sage. 
Rappleye, J., \& Komatsu, H. (2018). Stereotypes as Anglo-American exam ritual? Comparisons of students' exam anxiety in East Asia, America, Australia, and the United Kingdom. Oxford Review of Education, 44(6), 730-754.Available at: https://doi.org/10.1080/03054985.2018.1444598.

Rees, G., \& French, R. (2010). Leading, managing and developing people. London, UK: Chartered Institute of Personnel and Development.

Sergiovanni, T. (1967). Factors which affect satisfaction and dissatisfaction of teachers. Journal of Educational Administration, 5(1), 6682.Available at: https://doi.org/10.1108/ebo09610.

Syverson, S. (2007). The role of standardised tests in college admissions: Test-Optional admissions. New Directions for Student Services, 118 , 55-70.Available at: https://doi.org/10.1002/ss.241.

Thomas, D. R. (2006). A general inductive approach for analysing qualitative evaluation data. American Journal of Evaluation, 27(2), 237246.Available at: https://doi.org/10.1177/1098214005283748.

Ullman, J. (2020). Present, yet not welcomed: Gender diverse teachers' experiences of discrimination. Teaching Education, 31(1), 6783.Available at: https://doi.org/10.1080/10476210.2019.1708315.

Weiner, L. (2012). The future of our schools: Teachers unions and social justice. Chicago, IL: Haymarket Books.

Weiner, L., \& Jerome, D. (2016). Urban teaching: The essentials (3rd ed.). New York: Teachers College Press.

Weißenrieder, J., Roesken-Winter, B., Schueler, S., Binner, E., \& Blömeke, S. (2015). Scaling CPD through professional learning communities: Development of teachers' self-efficacy in relation to collaboration. ZDM, 47(1), 27-38.Available at: https://doi.org/10.1007/s1 1858-015-0673-8.

Xiao, Y., \& Hu, J. (2019). The inheritance and spreading of confucianism in modern China and South Korea. Paper presented at the Proceedings of the 2019 5th International Conference on Social Science and Higher Education (ICSSHE 2019). 